\title{
INFLUENCE OF HANDLING PROCESSES FOR BROILERS ON MORTALITY AND CARCASS QUALITY AT SLAUGHTERHOUSE
}

\author{
F. A. A. Hassan * and A. I. Lashin **
}

\begin{abstract}
The current study was conducted during spring and summer of 2016 and winter of 2017 at Al-Watania Poultry Company. A preliminary test was performed to identify the optimum operating conditions of a proposed mechanical catching machine (CIEMME Super Apollo L) and compare the effect of using this machine versus manual catching under commercial conditions, with respect to the performance rate; operation and production costs at the optimum operating conditions and the "welfare" stress indices, which were concentration of Corticosterone "CORT"; Adrenocorticotropic "ACTH"; glucose and lactate with tonic immobility as ant-mortem stress indices and dead on arrival "DOA"; the incidence of bruises and the rate of downgrade carcass quality as postmortem stress indices. The preliminary test results indicated that, the optimum operating conditions for the proposed catching machine were forward speed of 0.1 $\mathrm{m} / \mathrm{sec}$. and collection belt speed of $0.65 \mathrm{~m} / \mathrm{sec}$. at these conditions the recorded machine productivity were 20.66 and 20.59 ton/h and the recorded losses were 0.049 and $0.06 \%$ at MBM of 1600 or $2000 \mathrm{gm}$. respectively. The main test results indicated that, the performance rate of catching machine ranged from 8227 to $10418 \mathrm{Bird} / \mathrm{h}$. Meanwhile it was ranged between 4474 to 5317 Bird/h. with manual catching. The average catching costs for the mechanical and manual method was 9.48 L.E/ton and 44.7 L.E/ton respectively. As far the stress indices, the mechanically caught broilers had lower CORT concentrations and shorter durations of tonic immobility. That means ' mechanical catching b birds were less stressed than the manually caught. There is a positive feedback mechanism between CORT and glucose; lactate and duration of tonic immobility. Meanwhile there is a negative feedback mechanism between concentration of CORT and ACTH hormones.
\end{abstract}

\footnotetext{
*Bio-Eng. Dep., Ag. Eng. Res. Inst., Ag. Res. Center, Dokki, Giza, Egypt. **Chemistry Dep., Animal Health Res. Inst., Ag. Res. Center, Egypt.
} 
The highest DOA was $0.76 \%$ and $0.53 \%$ recorded with manual catching at summer and winter respectively, while it was 0.439 and 0.409 with mechanical catching at summer and winter respectively, with transport distance of $>250 \mathrm{~km}$ and mean body mass "MBM" of $2000 \mathrm{~g}$. The contusion of wing was reduced from $3.81 \% ; 3.27 \%$ for broiler caught manually to $3.02 \% ; 2.18 \%$ for broilers caught mechanically. However, there was no difference in contusions in the breast or paw between the two catching methods. Therefore, it can be concluded that the use of the broilers mechanical catching machine, CIEMME Super Apollo L, appears to be a good alternative to manual catching from the worker's; bird's welfare and economic point of view.

Keywords: Broilers; welfare; mechanical catching; optimum operating conditions; stress indices; mortality and carcass quality.

\section{INTRODUCTION}

$\mathrm{E}$ gypt produced 892.64 million poultry birds ( 1.785 billion ton) for meat, M.A.E.A.S. (2015). The increased rearing number of poultry and the demand for poultry to be centered and slaughtered in processing plants make handling processes "catching; crating; loading; transporting and unloading" a critical constituent in poultry industry all over the world. There are 299 slaughterhouses distributed all around Egypt M.A.E.A.S. (2015). When the birds reach market weight, they must be caught and crated, to transport from production facilities to processing plants. Catching and loading of the birds might be the most important processes, because if birds are injured during them, it could have a profound effect on their responses to the rest of their journey to the slaughter plant, Whiting et al. (2007). Virtually every aspect of broiler production has been automated over the past few decades except for the catching process, Lacy and Czarick (1998). The broilers are still caught manually by the leg and carried in an inverted position with 3-4 birds in each hand, Nijdam et al. (2005). Prior to catching, they have feed and water withdrawn to reduce intestinal content at the time of slaughter. The process of catching often causes them to suffer from stress, fear and injury due to panic among the birds and by rough handling. Hand catcher is frequently rated as one of the worst jobs in the poultry industry. It is a 
backbreaking performed in a dusty and dirty environment. The catching procedure is labor intensive and stressful for both the catchers and the birds, SCAHAW (2000). Fatigue due to the physical strain put on the catchers may even result in rougher handling and more broiler welfare problems. Assuming a catcher is expected to catch at least $1,000 \mathrm{birds} / \mathrm{h}$. and each bird weighs approximately $2 \mathrm{~kg}$, during an average 8-hour shift; an employee may lift 6 to 16 metric tons of broilers, Delezie (2006). The concern for welfare of animals and people has led to the production of mechanical catchers that are currently in use in the poultry industry, Schilling et al. (2008). Several types of broiler catching machines have been proposed but only those that use sweeping mechanisms provided with soft rubber fingers have been successfully developed commercially. Advantages of automated harvesting systems compared to manual catching are of lower costs, less bird stress, less damage, broken wings, bruises and less dead animals on transport, as well as improve working conditions for live haul personnel, Lacy and Czarick (1998); Gocke (2000) and Remmer (2011). Mechanical catching prevents broilers from being carried in an inverted position and from coming into direct contact with people during the catching and crating procedure. Inverted handling increases the duration of tonic immobility, and elevates plasma corticosterone "CORT" concentrations indicating that birds are more stressed, Delezie et al. (2006). Kannan and Mench (1996) and Nijdam et al. (2005) investigated some biochemical parameters, including levels of CORT, glucose and lactate. They found that plasma levels increased at the start of catching, and they further increased during transport, shackling and stunning. Knowles and Broom (1990) stated that, mortality records during journeys are often the only record which gives information about welfare and the severity of the problems for the animals. Nijdam et al. (2006); noted that birds that have died between catching and moment of slaughter are termed Dead on Arrival "DOA". Mean percentages of DOA birds range from 0.05 to 0.57 . Some identified factors associated with DOA \% in broilers are ambient temperature, harvesting company, time for harvesting, breed, flock size, mean body weight, mean stocking density, transport time, lairage time. Disadvantages of the mechanical catching are only possible in larger houses. As these are large machines, 
extra transport must be provided which increases the costs. The use is not possible in houses with two levels. The cleaning and disinfection of automated harvesting machines poses a major problem. Harvesting rubber fingers are extremely difficult to clean, e.g. for Salmonellae and Campylobacter meaning that the next flock may become infected, and thus resulting in a farm-to-farm cross contamination، Löhren (2012).

The main objectives of this research were as follows:

1- Identify the optimum operating conditions of a proposed "CIEMME Super Apollo L" catching machine.

2- Compare the effect of using catching machine at the optimum condition versus manual catching under commercial conditions with respect to; a- performance rate; b- productivity and c- operating costs as well as animal welfare (anti/post mortem stress indices); dmortality rate; e- the incidence of bruises and f- carcasses quality at slaughter house. This will assist the commercial poultry producers to reach a conclusion about the validity of mechanical catching as an alternative for manual catching.

\section{MATERIALS AND METHODS}

\subsection{MATERIALS:}

\subsection{1: Broilers farms:}

This study was conducted at Alwatania Processing Plant, Nabaa AlHamra village "Wady Al-Nattrown, El-Bhara Governorate", during the period March 2016 to February 2017. By using 24 commercial broilers farms originated from breed Cobb 500, with dimensions of (18 m wide $\times$ $80 \mathrm{~m}$ long), usually holds 15,000 to 20,000 broilers, depends on the size of the bird and the stocking density 20 birds $/ \mathrm{m} 2$. Distance between broilers farms and slaughter houses ranged between less than $50 \mathrm{~km}$ to more than $250 \mathrm{~km}$. The broilers age ranged between 36 to 50 days with a range of mean body mass "MBM" between $\geq 1600$ to $\geq 2000 \mathrm{~g}$. All flocks were of mixed sexes.

\subsection{2: Catching methods}

\section{(a): Manual Catching}

Professional catching teams did the manual catching. Eight to ten catchers and one forklift truck driver formed a team. A catcher would grasp a 
broiler by the leg and invert the bird. After catching 6 to 8 birds, the catcher carried them to the nearest container with 3 to 4 birds in each hand and placed them into a compartment. The containers were placed within $10 \mathrm{~m}$ of the catching place.

\section{(b): Mechanical Catching.}

Table: (1) lists the technical specifications for the proposed catching machine "CIEMME Super Apollo L". Figure: (1) shows a schematic diagram for CIEMME Super Apollo L; and Figure: (2) shows frontal view for CIEMME Super Apollo L. The machine is stationed inside the poultry shed and prepared by opening the two wings of the front collection head, which are formed of individual blocks of conveyor belts. The operator starts the machine; activates the conveyor belts and slowly moves towards the animals, allowing them to climb onto the collection belts in a natural way that requires no mechanical force. These belts deposit the birds, without subjecting them to any sudden or stressful movements, onto the two transverse belts that lead to the central channel, where broilers are carefully transported to the upper part of the machine. Here, the caging belt directly deposits the birds into the container. With simple controls, the operator can raise or lower the belt, or move it nearer or further away. With the same controls, the operator can also move onto the next crate and start or stop the entire machine and all of its collection belts. By the automatic weighing system, the machine stops when it reaches the preset value, guaranteeing compliance with every regulation in force regarding animal density in the containers. Figure: (3) shows CIEMME Super Apollo L while working. The containers are positioned on a carousel, which with the aid of automatic movement, allows for a continuous loading process. Once a module is full, it is then ready for collection by the forklift, which places it on the lorry outside the poultry shed. Figure: (4) shows crate module on a carousel while caging. The catching process manually or by machine was conducted from 4 to 8 a.m. A movable, modular drawer crate system (1.2 m wide, $2.4 \mathrm{~m}$ long and 0.3 $\mathrm{m}$ high), designed for a capacity of about 21-22 in summer and 23 in winter, each weighing $2 \mathrm{~kg}$. At the processing plant the modules are unloaded onto a conveyor belt that transfers them close to the shackling 
line where the birds are removed when the modules are tipped and the birds slide out

Table: (1) The technical specifications for CIEMME Super Apollo L catching machine.

\begin{tabular}{|lr|}
\hline Harvesting head & From 3 to $9 \mathrm{~m}$ \\
\hline Width & $450 \mathrm{~mm}$ \\
\hline Machine weight & $4,800 \mathrm{~kg}$ \\
\hline Cage holder cart & $2,200 \mathrm{~kg}$ \\
\hline Cart weight (CR2) & 5 minutes \\
\hline Machine start-up time & $3-4$ \\
\hline Operators number & From 16 to 26 tonnes/h \\
\hline Load quantity & Kubota $2203 \mathrm{M}$ \\
\hline Motor Model & $34 \mathrm{~kW}(46 \mathrm{hp})$ \\
\hline Maximum power & $2200 \mathrm{cc}$ \\
\hline Cylinder capacity & $41 / \mathrm{h}$ \\
\hline Fuel consumption & \\
\hline
\end{tabular}

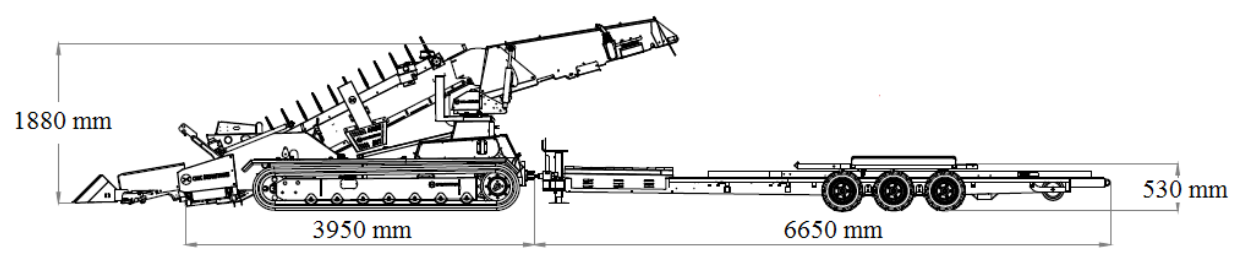

CR2 cart with 3 positions
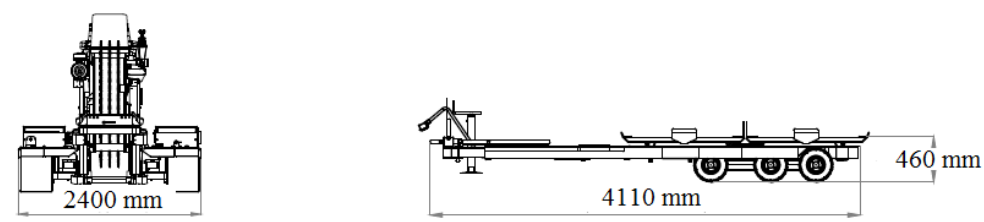

CR9 cart with 2 positions

Fig. 1: Schematic diagram for CIEMME Super Apollo L catching machine 


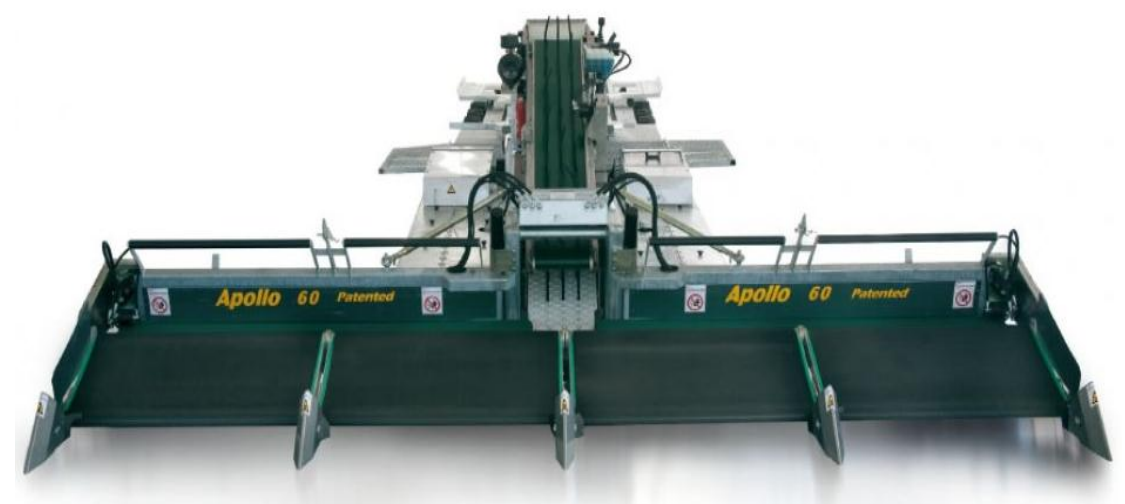

Fig. 2: CIEMME Super Apollo L catching machine front view

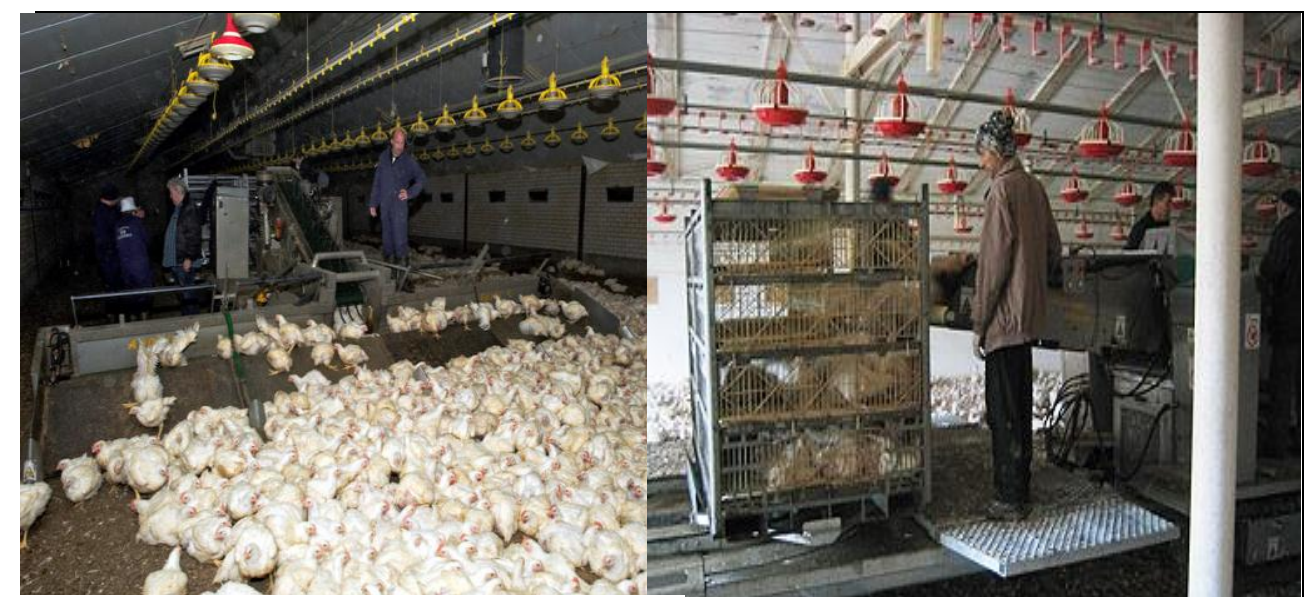

Fig. 3: CIEMME Super Apollo L catching Fig. 4: Crate module on a carousel machine while working. while caging broilers

\subsubsection{Experiments:}

- Preliminary test:

This test was carried out to identify the optimum operating conditions for the proposed catching machine that include: (machines' forward speed; collection belt speed and MBM of the broilers in relation with the machine productivity and Losses). The machine was tested under 8 levels of forward speed $(0.02$ to $0.16 \mathrm{~m} / \mathrm{sec}) ; 5$ speed levels of header collection belt $(0.2$ to $0.8 \mathrm{~m} / \mathrm{sec})$ and two MBM groups $(\leq 1600$ and $\geq 2000 \mathrm{~g}$.), by using 160 tagged modules transported by 14 truckloads. To eliminate the weather and transport's stress. This test depends on commercial broiler 
farms at a distance of less than $50 \mathrm{~km}$ to slaughter house, during spring (15/3 to $15 / 4$ 2016). Every treatment represented two modules. To evaluate the machine under different treatments, the following data were collected: modules broiler weight; catching and crating time; losses \% which include the dead birds from driver mistakes with the dead on arrival due to improper operating conditions.

- Main test:

This test was conducted to compare the effect of using CIEMME Super Apollo L catching machine at the optimum operating conditions versus manual catching, under commercial conditions with respect to performance rate; productivity and operating costs, as well as animal welfare (stress indices); mortality rate "DOA"; the incidence of bruises and carcasses quality at slaughter house. Two tests were conducted. The first was from May to August and the second from November to February. In terms of mechanical catching, 38 trucks of load "229900 broilers" were evaluated. Meanwhile corresponding number 34 trucks of load "205360 broilers" were caught manually. The following data were collected for every broiler house: season; MBM; flock size; catching time; transport distances and time; dead on arrival; bruises type and \% and quality level. Data were statistically processed with Excel 2010 program.

\subsubsection{Tests parameters:}

(1) Catching systems:

(a) Manual catching

(b) Mechanical "CIEMME Super Apollo L catching machine".

(2) Machine parameters:

(a) Forward speed: $(\mathrm{m} / \mathrm{sec}$.)
$1-0.02 \quad 2-0.04$
3- 0.06
4- 0.08
5- 0.10
6- 0.12 7- 0.14
8- 0.16

(b) Conveyor belt speed: $(\mathrm{m} / \mathrm{sec}$.)
$1-0.22-0.35$
3- 0.50
4- 0.65
5- 0.8

(3) Broilers farms parameters:

3-1: Mean body mass "MBM": The investigated broiler farms MBM were:
(a) $\leq 1600$ g. and
(b) $\geq 2000 \mathrm{~g}$. 
3-2: Transport distance: The investigated broiler farms are located at the following distance categories:
(a) $\leq 50 \mathrm{~km}$;
(b) $51: 100 \mathrm{~km}$;
(c) $101: 150 \mathrm{~km}$;
(d) $151: 200 \mathrm{~km}$;
(e) 200: $250 \mathrm{~km}$; and
(f) $>250 \mathrm{~km}$.

3-3: Duration of sample collection: To investigate the stress physiological indices and tonic immobility, the samples were collected at the following duration:
(a) 45 minute before start catching.
(b) 15 minute after catching.
(c) Immediately after arrival to the slaughter house.

3-4: Season: Three test trails were performed for this study:

(a) $1^{\text {st }}$ (preliminary test) at spring of $2016(15 / 3$ to $15 / 4)$;

(b) $2^{\text {nd }}$ at summer of $2016(15 / 5$ to $15 / 8)$ and

(c) $3^{\text {rd }}$ at winter of $(15 / 11 / 2016$ to $15 / 2 / 2017)$.

\subsubsection{Measurements:}

1- Performance rate (P.R.) and productivity: were estimated by using the following equations:

P.R., Bird/h = Flock size $\times 60 /$ catching time $(\mathrm{min})$

Productivity $($ ton $/ \mathrm{h})=\mathrm{P} . \mathrm{R}(\mathrm{B} / \mathrm{h}) \times \mathrm{MBM} / 1000$

Where:

MBM of $=2000 \mathrm{gm}$.,

\section{Cost: L.E./ton}

2.1: Manual catching costs (M.C.C.) (L.E/ton).

M.C.C. $=[($ Daily costs of catching crew) / D.W.H] / (P.R) (ton/h)-- (3)

Where:

Typical catching crew $=8-10$ workers.;

Worker daily salary $=200$ L.E. and

D.W.H $=$ Daily working hours $=8$ hours.

2.2:- Mechanical catching costs: The machine cost and total operating costs of catching machine were estimated using the following equations (Awady, 1978):

$$
\text { Operating cost }=\frac{\text { Machine cost }(\mathrm{L} . \mathrm{E} / \mathrm{h})}{\text { Machine productivity }(\text { ton } / \mathrm{h})}(\text { L.E./ton })
$$

Machine costs were determined by using the following equation 


$$
\mathrm{C}=\frac{\mathrm{P}}{\mathrm{h}}\left(\frac{1}{\mathrm{a}}+\frac{\mathrm{i}}{2}+\mathrm{t}+\mathrm{r}\right)+(\mathrm{W} . \mathrm{e})+\frac{\mathrm{m}}{144}
$$

Where:

$\mathrm{C}=$ Machine cost, L.E/h.

$\mathrm{h}=$ Yearly working hours,

$\mathrm{i}=$ Interest rate/year.

$\mathrm{t}=$ Taxes; overheads ratio.

$\mathrm{m}=$ Monthly average wage, $\mathrm{L} . \mathrm{E}$
$\mathrm{P}=$ Price of machine, L.E.

$\mathrm{a}=$ Life expectancy of the machine, $\mathrm{h}$.

$\mathrm{e}=$ hourly cost $/ \mathrm{kW} \cdot \mathrm{h}$.

$\mathrm{r}=$ Repairs and maintenance ratio.

$\mathrm{W}=$ Power of motor in $\mathrm{kW}$.

$144=$ Reasonable estimation of monthly working hours.

3. Stress (poor welfare) or "Fearfulness": was measured before slaughter (Ante mortem) by using the physiological indices which were concentration of Corticosterone "CORT"; Adrenocorticotropic "ACTH" hormone; glucose, and lactate in plasmas, and the behavioral indices "Tonic immobility" (TI). As well as after slaughter (Post mortem) by using DOA's; Bruises $\%$ and carcass quality downgrade.

\section{1: Physiological indices "Blood biochemical parameters":}

To measure physiological stress indices for each method, a total of $1 \wedge 0$ samples were selected randomly from four broiler houses with regular harvesting age 42 day and $\mathrm{MBM} \geq 2000 \mathrm{~g}$, with transport distance category (100-150 km). Fifteen samples from each house collected at three durations. 60 samples at 45 minute before start catching, 60 samples at 15 minute after catching and 60 samples immediately after arrival to the slaughter house. Blood samples $(3.0 \mathrm{ml})$ were withdrawn from the brachial vein in the broilers of each test group by simple venipuncture. The blood samples, containing without anticoagulant then centrifuged at $3000 \mathrm{~g}$ for $10 \mathrm{~min}$ using bench top centrifuge. Sera were separated and were collected using dry Pasteur pipette for estimation glucose and lactate concentration measured by using spectrophotometer. Also the serum CORT and ACTH concentration were measured by radio-immunoassay kit using Mini Vidas (PCR).

3.2.: Behavioral indices: Tonic immobility test (TI):

According to Delezie et al. (2005) and Zulkifli et al. (2000). Alive bird samples were chosen and tested individually for duration of TI in a 
separate room, gently restrained on their back, on a table covered with multi layers of clothes, for a period of $15 \mathrm{sec}$. by putting one hand on the sternum and the other on the neck of the bird. Latency was recorded until the bird righted itself. A score of $0 \mathrm{sec}$. for duration of TI was given, if TI of the bird was not induced after 5 trails. If TI lasted longer than $10 \mathrm{~min}$, the maximum score of $600 \mathrm{sec}$. was given for TI duration. A total of 120 samples were selected randomly from 4 broiler houses with transport distance category 100-150 km, with $\mathrm{MBM} \leq 1600$ and $\geq 2000 \mathrm{~g}$. 60 samples from each MBM group, where 20 samples for each duration. No bird was sampled more than once.

\section{3.: DOA's and bruises \%:}

The number of DOA's was counted at the slaughter house during shackling the birds for each load. Injuries due to catching, loading/unloading was determined at the slaughter house. For each 2000 broilers within one load, 100 carcasses were selected randomly to evaluate its quality at the platform next to the veterinary supervision. Bruises type and percentage on the wings, thighs and breast meat, fractures and luxation of "wings and thighs"; break of "wings and paw" and mechanical damage were counted.

\section{4.: Carcasses quality:}

The carcasses were classified into three quality classes by the slaughterhouse authorized as noted by Steinhauser, et al. (2000).Where, Class I and II are considered as standard meat quality. The difference between them is the meatiness, age, size of broilers and processing quality. Broilers which are not very different from standard are included into grade II. Not-standard carcasses are classified into grade III.

\section{1: Preliminary test results:}

\section{RESULTS AND DISCUSSION}

Fig. 5 shows effect of machine forward speed; collection belt speed and MBM on machine productivity and losses, \%. The highest values of machine productivity were 20.66 and 21.38 ton/h. recorded with MBM 1600 and $2000 \mathrm{gm}$. respectively at machine forward speed $0.12 \mathrm{~m} / \mathrm{sec}$. and collection belt speed $0.65 \mathrm{~m} / \mathrm{sec}$. 
(A) Belt speed, $0.2 \mathrm{~m} / \mathrm{sec}$.

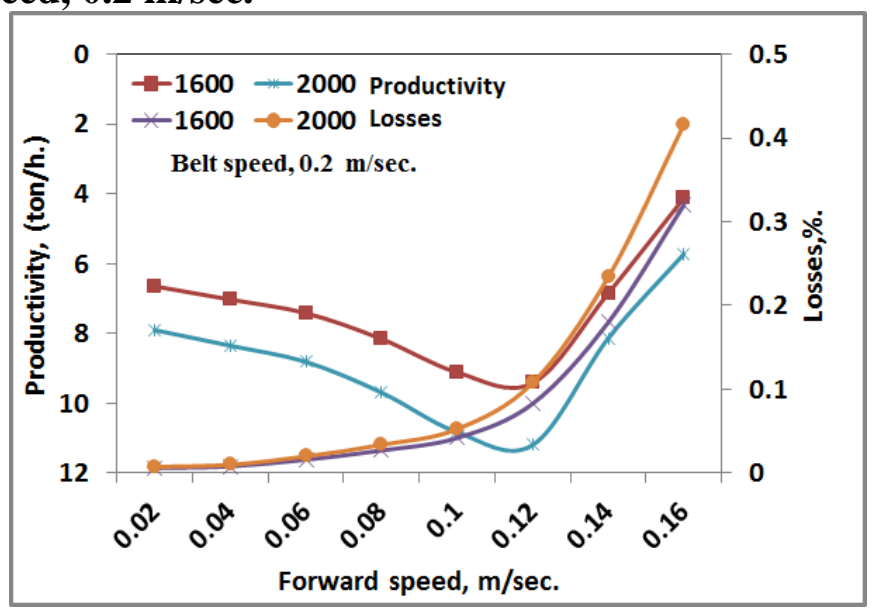

( B ) Belt speed, $0.35 \mathrm{~m} / \mathrm{sec}$.

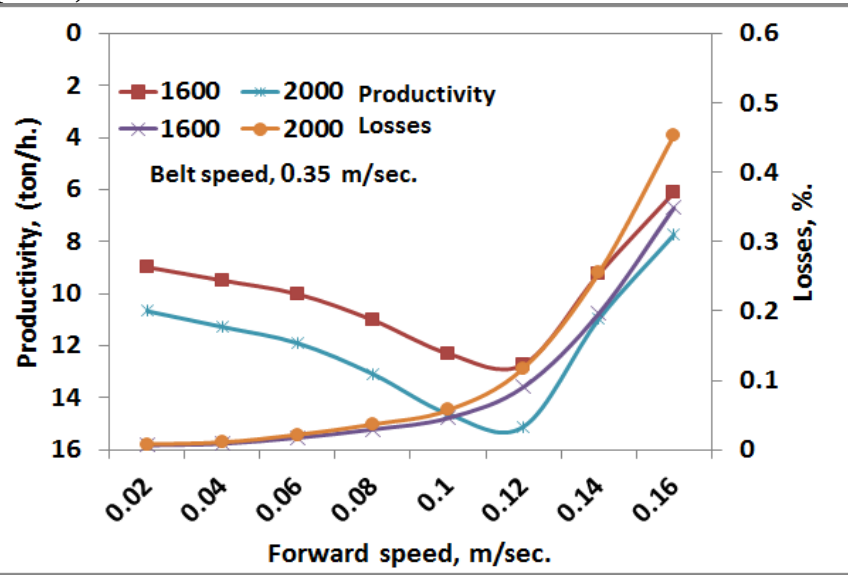

( C ) Belt speed, $0.50 \mathrm{~m} / \mathrm{sec}$.

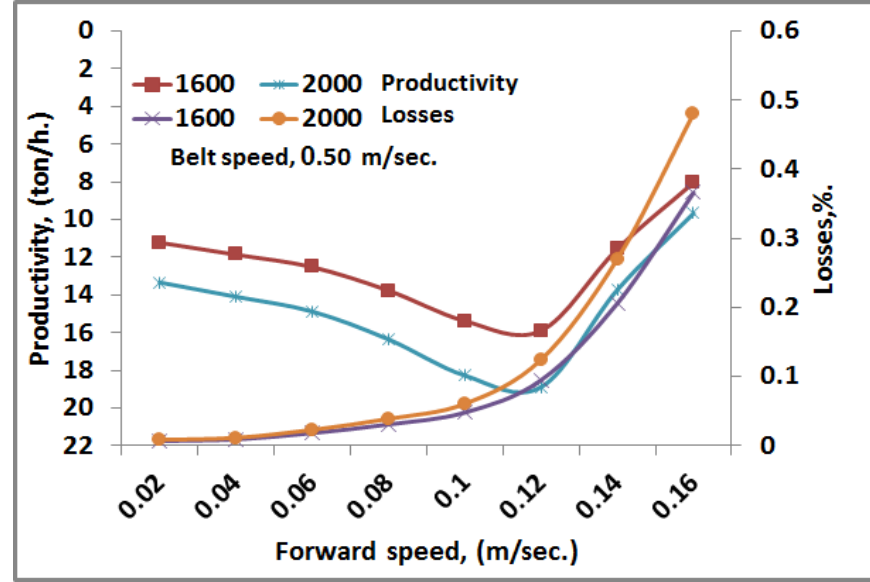

Misr J. Ag. Eng., October 2017 
(D) Belt speed, $0.65 \mathrm{~m} / \mathrm{sec}$.

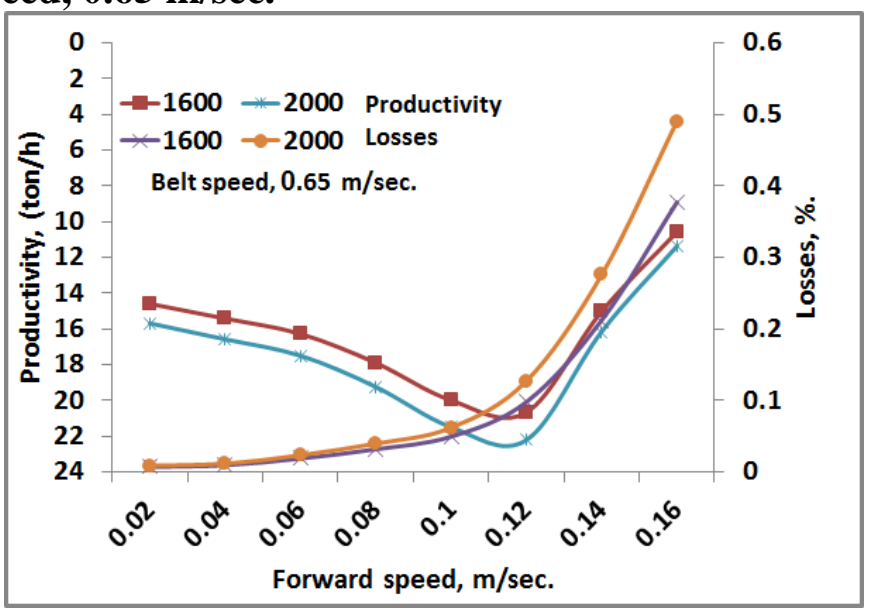

(E) Belt speed, $0.8 \mathrm{~m} / \mathrm{sec}$.

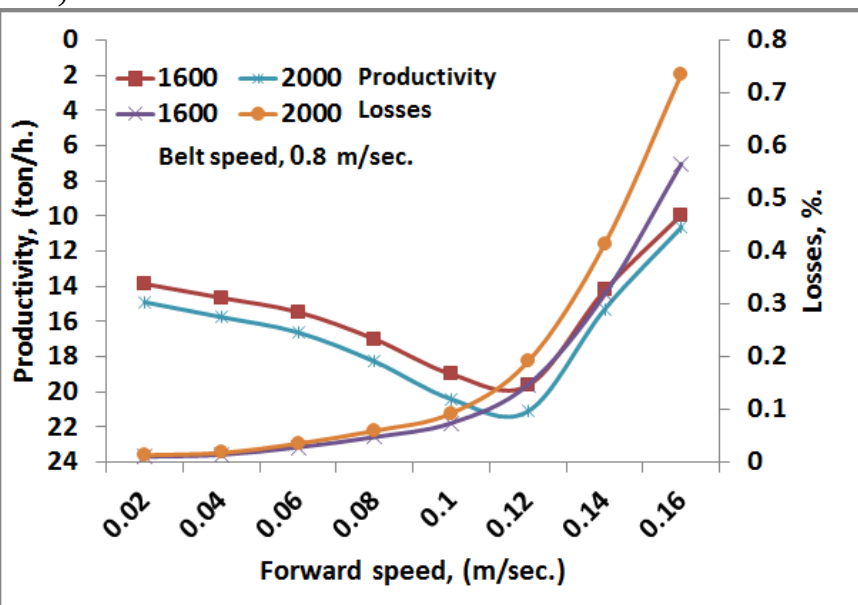

Fig. 5(A; B; C; D and E): Effect of forward speed; collection belt speed and MBM on machine productivity and losses, $\%$.

Meanwhile, the lowest values of machine productivity were 4.82 and 5.73 ton/h. recorded with MBM 1600 and 2000 gm. respectively at machine forward speed $0.16 \mathrm{~m} / \mathrm{sec}$. and collection belt speed $0.2 \mathrm{~m} / \mathrm{sec}$. On the other hand, the highest values of machine losses were 0.56 and $0.735 \%$. recorded with MBM 1600 and $2000 \mathrm{gm}$. respectively at machine forward speed $0.16 \mathrm{~m} / \mathrm{sec}$. and collection belt speed $0.8 \mathrm{~m} / \mathrm{sec}$. Meanwhile the lowest values of machine losses were 0.006 and $0.0075 \%$, recorded with MBM 1600 and $2000 \mathrm{gm}$. respectively at machine forward speed 0.02 $\mathrm{m} / \mathrm{sec}$. and collection belt speed $0.2 \mathrm{~m} / \mathrm{sec}$. The optimum operating 
conditions of the proposed CIEMME Super Apollo L catching machine were forward speed of $0.1 \mathrm{~m} / \mathrm{sec}$. and collection belt speed of $0.65 \mathrm{~m} / \mathrm{sec}$. At these operating conditions, the recorded machine productivities were 20.66 and 20.59 ton/h and the recorded losses were 0.049 and $0.06 \%$, at MBM of 1600 or $2000 \mathrm{~g}$ respectively.

\section{2: Main test results}

\section{(1) Effect of catching method; MBM and season on performance rate.}

Fig. 6 shows the effect of catching method and season on performance rate. The highest values of performance rates for manual and mechanical catching were 5317 and $10418 \mathrm{bird} / \mathrm{h}$ respectively in summer season, with MBM 1600g. This means 10,634 and 20,836 ton/h prevailed respectively. Meanwhile, the performance rate in summer for the manual and mechanical catching with MBM 2000 g. was 5164 and 9318 bird/h. This means 10,328 and 18,636 ton/h. lowest values of performance rates for manual and mechanical catching were 4474 and $8227 \mathrm{bird} / \mathrm{h}$ respectively in winter, with MBM 2000g. This means, 8,948 and 16,454 ton/h. Generally, the machine performance rates nearly 2 times greater than manual catching
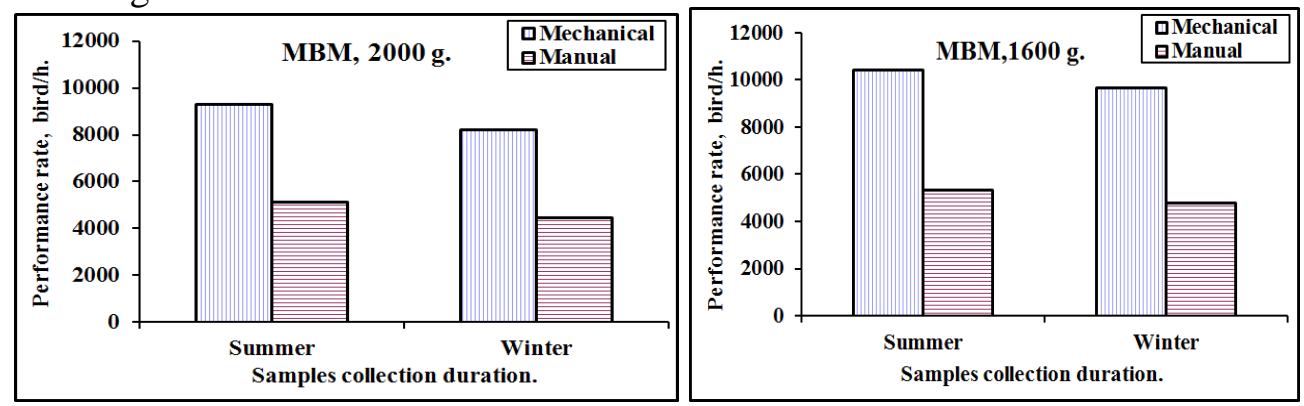

Fig. 6: Effect of catching method; MBM and season on performance rate.

\section{(2) Effect of catching method on production costs}

(a) Operating cost: The operation costs for manual and mechanical catching only were 400 and $159.04 \mathrm{~L}$.E/h respectively.

- The cost of the forklift and the driver was 159.04 add to the costs for each system. Then, the total operating costs for the manual and mechanical catching system were 559.04 L.E/h and 318.07 L.E/h.

(b) Production costs: The production costs at optimum conditions for manual and mechanical catching only (without forklift's cost) were 37.62 
and 7.48 L.E/ton respectively in summer season with MBM 1600g. Meanwhile, the production costs for manual and mechanical catching system were 44.70 and 9.48L.E/ton respectively in winter season with MBM 2000g. These results are in agreement with those reported by lacy and Czarick (1998) the labour costs for a typical nine person manual catching crew at $\$ 215.000 / \mathrm{yr}$. comparatively, the labour costs for a three to four person crew required to operate a mechanical harvester were estimated at $\$ 72.000 / \mathrm{yr}$, which represent a cost saving of $\$ 143.000 / \mathrm{yr}$.

\section{(3) Effect of catching method and season on stress indices of broilers:}

\section{1- Physiological indices:}

\section{1-1: Corticosterone concentration.}

Fig. 7 "A" shows effect of catching method, season and duration of sample collection on corticosterone "CORT" concentration. The normal "baseline level" of CORT concentration before catching was $10.54 \mathrm{ng} / \mathrm{ml}$. It increased to 37.32 and $33.2 \mathrm{ng} / \mathrm{ml}$. with manual catching at summer and winter respectively with MBM 2000g. and transport distance of 100:150 $\mathrm{km}$. Meanwhile, CORT concentrations reached to maximum level to 47.22 and $49.18 \mathrm{ng} / \mathrm{ml}$ after arrival when using manual method at summer and winter seasons respectively with $\mathrm{MBM}$ of $\geq 2000 \mathrm{~g}$. and transport distance of 100: $150 \mathrm{~km}$. On the other hand, CORT concentrations recorded with mechanical method were 19.34 and $18.3 \mathrm{ng} / \mathrm{ml}$ during catching and 38.18 and $34.69 \mathrm{ng} / \mathrm{ml}$ after arrival at summer and winter respectively. It means that, using mechanical catching decreased the level of CORT concentrations and stress during catching compared with manual method. This was consistent with observation by Kannan and Mench (1996) catching and crating will cause stress. Handling of broiler in inverted position lead to an increase in CORT concentrations. Cockrem (2007) CORT concentrations in birds usually increase rapidly for 10 to 15 min after capture and then increase more slowly.

\section{1-2 ACTH concentration}

Fig. 7 "B" shows effect of catching method, season and duration of sample collection on ACTH concentration.

The normal "baseline" level of ACTH concentration before catching was $90.81 \mathrm{Pg} / \mathrm{ml}$. It slightly increased to 116.42 and $98.98 \mathrm{Pg} / \mathrm{ml}$ at summer and to 109.11 and $93.99 \mathrm{Pg} / \mathrm{ml}$ at winter during mechanical and manual 
catching respectively. Meanwhile, the minimum level of ACTH concentrations was 62.17 and $54.98 \mathrm{Pg} / \mathrm{ml}$ at summer. The corresponding values at winter were 61.77 and $54.9 \mathrm{Pg} / \mathrm{ml}$ recorded after arrival when using mechanical and manual catching respectively with MBM of 2000g and transport distance of 100: $150 \mathrm{~km}$. It means that, there is a negative feedback mechanism between concentration of ACTH and CORT hormone, where the level of ACTH concentrations decreased with increased level of CORT. Kreger (1992) Stated that, Increased levels of corticosteriods can inhibit ACTH release from the anterior pituitary in a negative feedback loop.

\section{1-3: Lactate concentration}

Fig. 7 "C" shows effect of catching method, season and duration of sample collection on lactate concentration.

The normal" baseline" level of lactate concentration before catching was of $17.11 \mathrm{mmol} / \mathrm{l}$. It increased to 48.8 and $58.1 \mathrm{mmol} / \mathrm{l}$ during catching by using mechanical and manual catching respectively in summer season. The maximum lactate concentrations of 65.25 and $71.04 \mathrm{mmol} / \mathrm{l}$ were obtained from serum samples taken after arrival using manual catching for summer and winter season respectively.

It is clear that the level of lactate concentration increased during catching and after arrival compared with its baseline level before start catching by using either manual or mechanical catching. It is a physiological response due to stress affected on the birds during the handling processes. The increased level of lactate concentration after arrival compared with during catching means that the birds were subjected to additional stress due to transport. On the other hand, using mechanical catching decreased the level of lactate concentration stress during catching compared with manual method.

\section{1-4: Glucose concentration.}

Fig. 5 "D" shows effect of catching method, season and duration of sample collection on glucose concentration.

The normal" baseline" level of glucose concentration before catching was $209.9 \mathrm{mg} / \mathrm{dl}$. It increased to 218 and $223 \mathrm{mg} / \mathrm{dl}$ during catching by using mechanical and manual catching respectively in summer season. The maximum glucose-concentration of 231.6 and $221 \mathrm{mg} / \mathrm{dl}$ was recorded 
with serum samples taken after arrival using manual and mechanical catching in summer season. It is clear that, the level of glucose concentration increased during catching and after arrival compared with its baseline level before start catching by using either manual or mechanical catching. The increased level of glucose concentration after arrival compared with during catching mentioned that, the birds were subjected to the highest level of stress during transport. On the other hand, using mechanical catching decreased the glucose concentration compared with manual catching.

\section{(b) Behavioral index (Tonic immobility).}

Fig. 8 shows the effect of catching method, season and duration of sample collection on tonic immobility.

The mean periods of tonic immobility recorded before catching was 64 sec. The maximum tonic immobility of 294 and $278 \mathrm{sec}$. was recorded in winter after arrival and during catching using manual methods. Meanwhile, the tonic immobility when using mechanical catching in winter was of 243 and $202 \mathrm{sec}$. obtained after arrival and during catching. These results are in agreement with those reported by Jones (1992) Handling of broiler in inverted position lead to prolonged tonic immobility reaction. Also, Duncan (1989) compared the physiological parameters of birds harvested manually to those harvested by a prototype of a rotating rubber finger harvester. The time required returning to normal heart rate and duration of tonic immobility was significantly lower in birds caught by the mechanical harvester.

\section{(4) Effect of catching method, season and transport distance on "dead on arrival" "DOA".}

Fig. 9 shows effect of catching method, MBM; season and transport distance on "dead on arrival" "DOA". The maximum percentage of "DOA" of 0.759 and $0.530 \%$ were obtained by using manual catching at transport distance of $>250 \mathrm{~km}$ for summer and winter seasons respectively with MBM 2000g.,while it was 0.44 and 0.41 obtained by using mechanical catching with the same conditions. The minimum "dead on arrival" "DOA" values of 0.125 and $0.108 \%$ were obtained by using mechanical catching at transport distance of $<50 \mathrm{~km}$ 


\section{A-Corticosterone.}
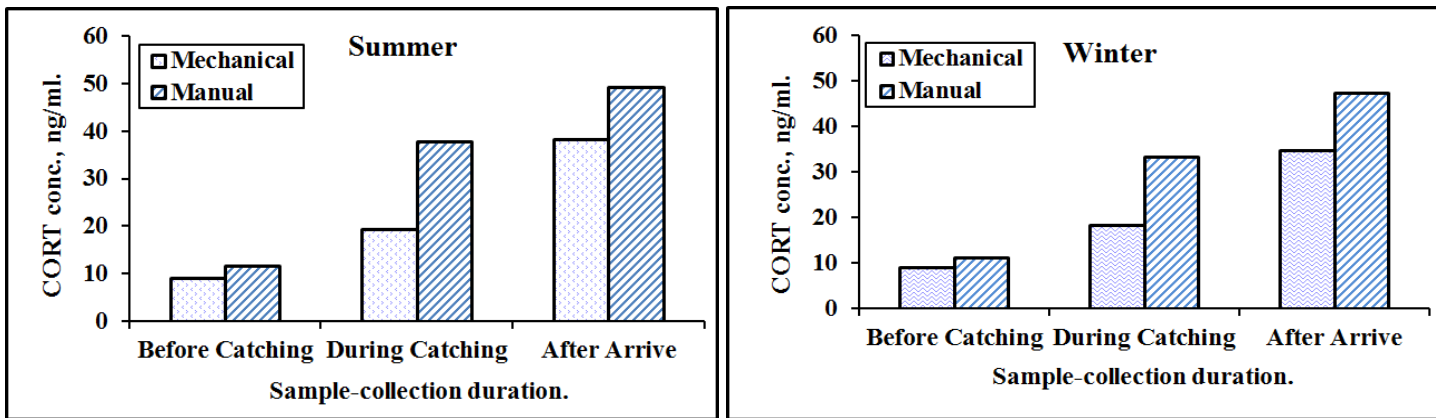

\section{B-ACTH.}
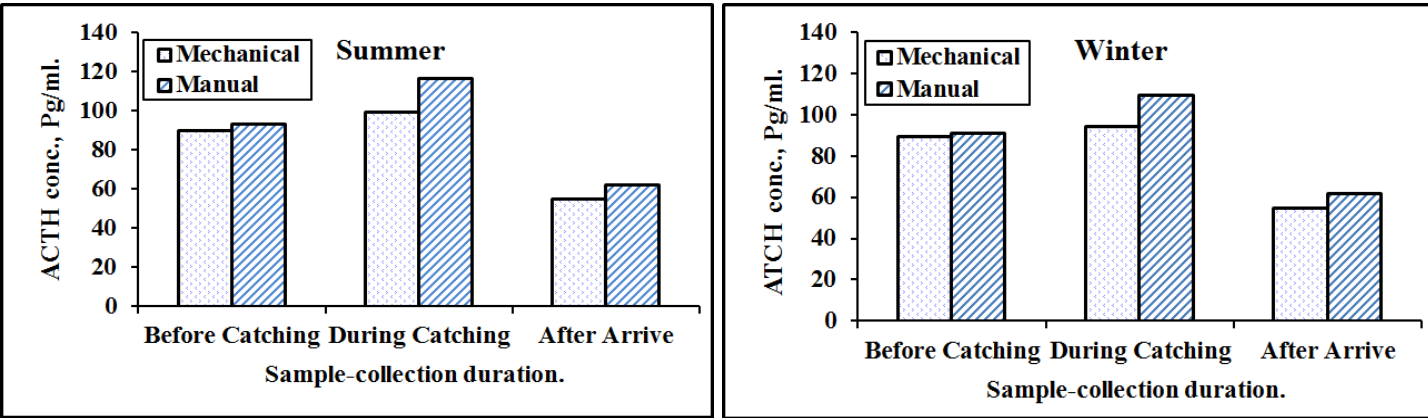

\section{C-Lactate.}
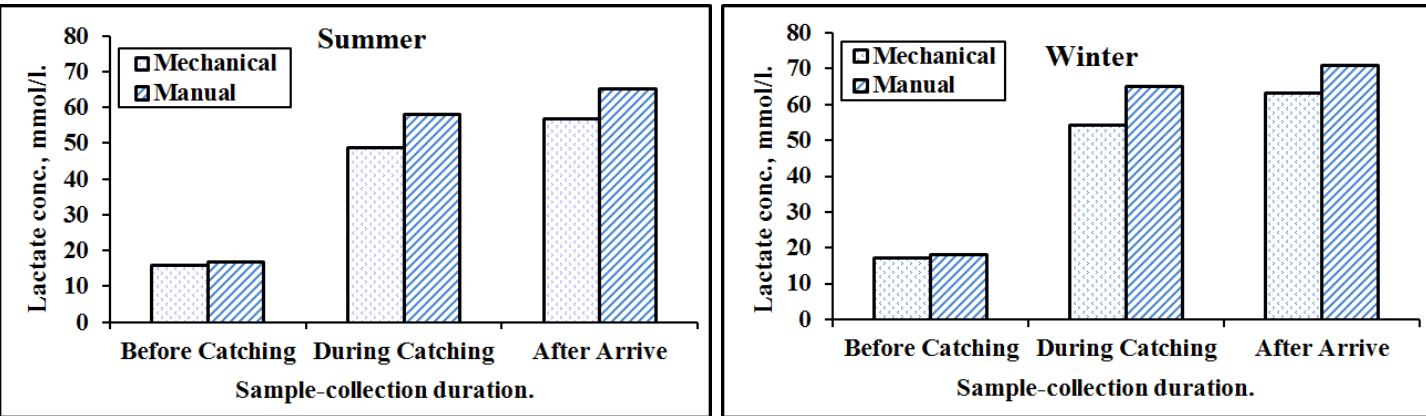

\section{D-Glucose.}
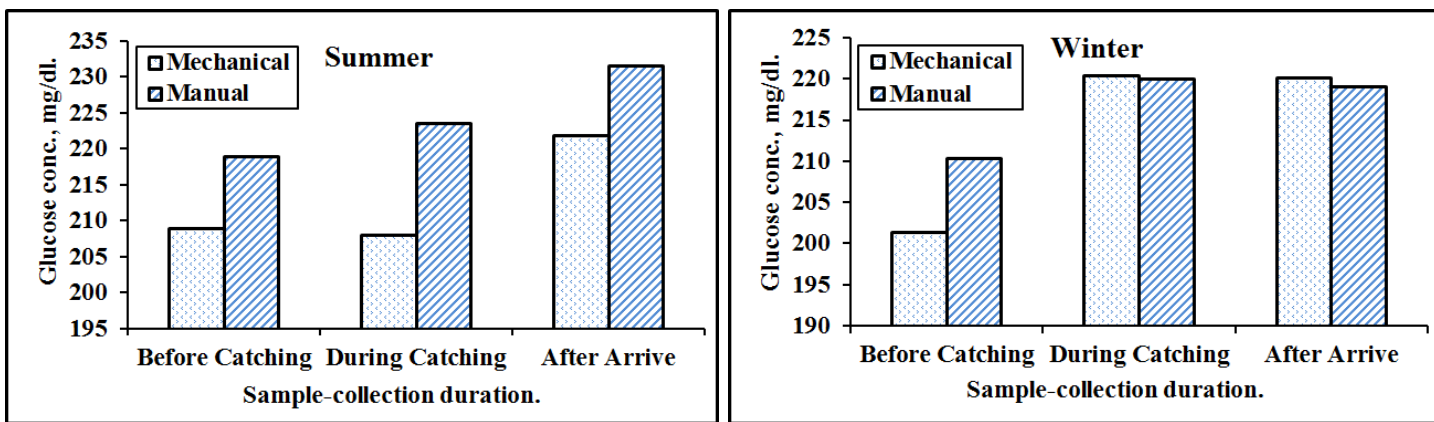

Fig. 7: Effect of catching method, season and duration of sample collection on concentration of (A) Corticosterone; (B) ACTH (C) Lactate and (D) Glucose. 


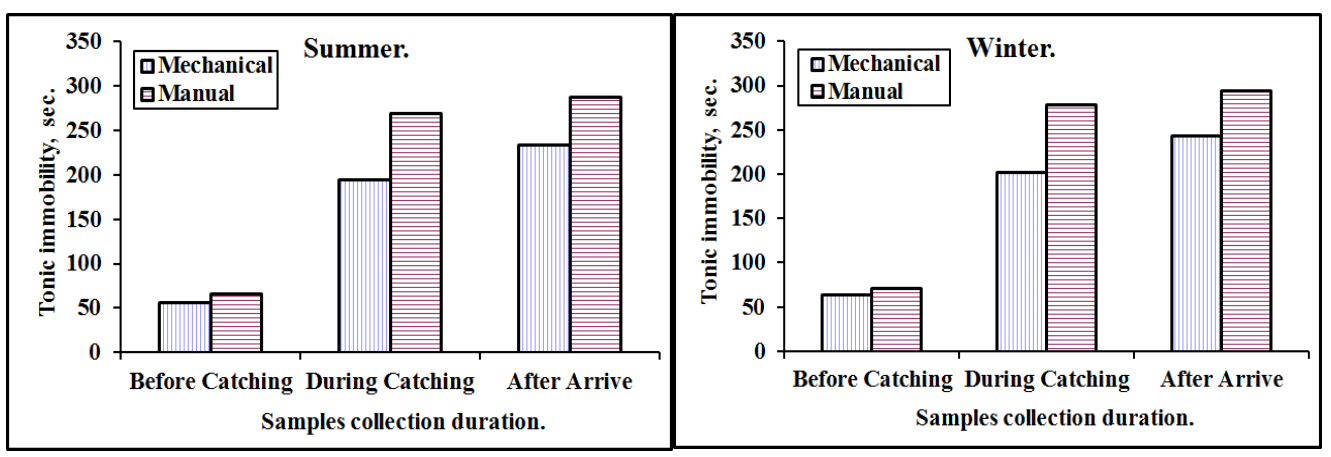

Fig. 8: Effect of catching method, season and duration of sample collection on tonic immobility.

for summer and winter seasons respectively with MBM 1600g. It is clear that, the percentage of "DOA" decreased when using mechanical catching instead of manual catching at all transport distances during summer or winter season with MBM 2000g and $1600 \mathrm{~g}$. Also, the total percentage of "DOA" decreased when using mechanical method with MBM 1600g. This means that, using mechanical catching with MBM 1600g. at lowest transport distance between broiler farms improving, not only the birds welfare but also the quality of carcasses. Nijdam (2006) mentioned that, postmortem examination of DOA broilers revealed a prevalence of traumata of $29.5 \%$. It is likely that a substantial part of trauma, such as head trauma, and ruptured livers occurred during catching and crating. Therefore, manual catching must be improved.

\section{(5): Effect of catching method! MBM and season on types of bruises.}

Fig. 10: shows effect of catching method, MBM and season on types of bruises. The maximum total bruises values of 8.17 and $8.40 \%$ were obtained when using mechanical and manual catching respectively in summer seasons with MBM $2000 \mathrm{~g}$. Meanwhile the minimum total bruises values of 5.82 and $6.87 \%$ were obtained when using mechanical and manual catching respectively in winter seasons with MBM $1600 \mathrm{~g}$. Bruises of "Contusions type" in (wing; thigh and breast) were of 3.93; 0.73 and $0.69 \%$, respectively recorded with manual catching recorded with manual catching in summer with MBM $2000 \mathrm{~g}$. The corresponding values recorded with mechanical catching were of $2.12 ; 0.46$ and $0.52 \%$, respectively, at the same conditions. 


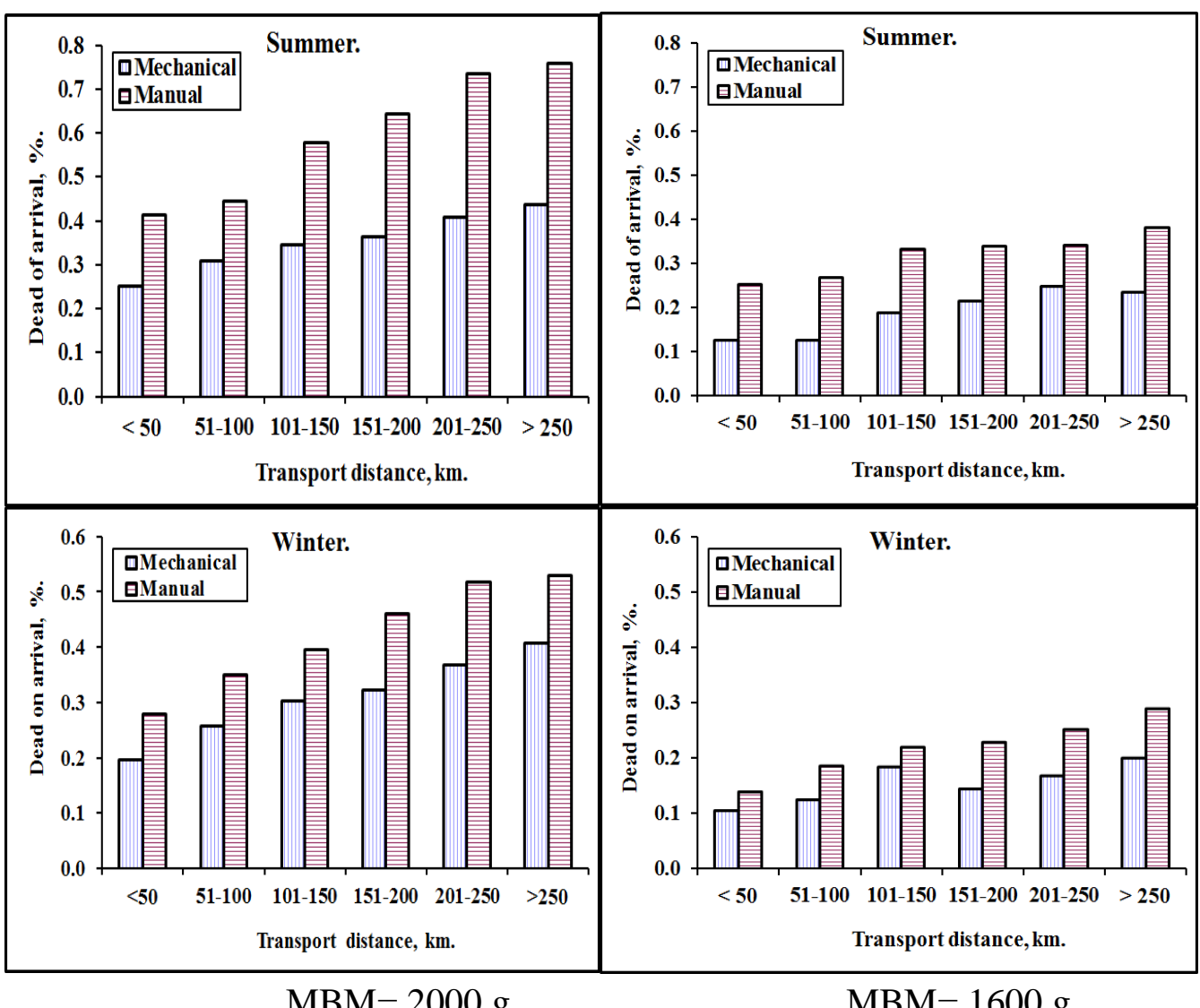

Fig. 9: Effect of catching method; MBM; season and transport distance on dead on arrival "DOA".

The mean values of bruises "Luxation type" were of $2.27 \%, 0.016 \%$ at (wings and paws respectively), recorded with mechanical catching in summer with MBM 2000g. The corresponding values recorded with manual catching were of $1.81 \%$ and $0.029 \%$, at the same conditions. The highest values of technical damages were of $1.23 \%$ and $0.67 \%$, recorded with mechanical and manual catching respectively in summer with MBM $2000 \mathrm{~g}$. Meanwhile the minimum technical damages were of $1.04 \%$ and $0.52 \%$ recorded with mechanical and manual respectively in winter with MBM 1600g. These results are in agreement with those reported by Ramasamy et al., (2004) and lacy and Czarick (1998) they compared the bruising rate of manual versus mechanical harvesting and report that leg bruising was reduced by more than $50 \%$ and there were also reductions 
in back and breast bruising when mechanical harvesting was used. However, a slight, non-significant increase in wing bruising was also observed. Theoretically, a manual catching crew can load the birds with no injuries but in real life stress to the birds and the people trying to catch them as well as time constraints usually result in a less than optimal situation.

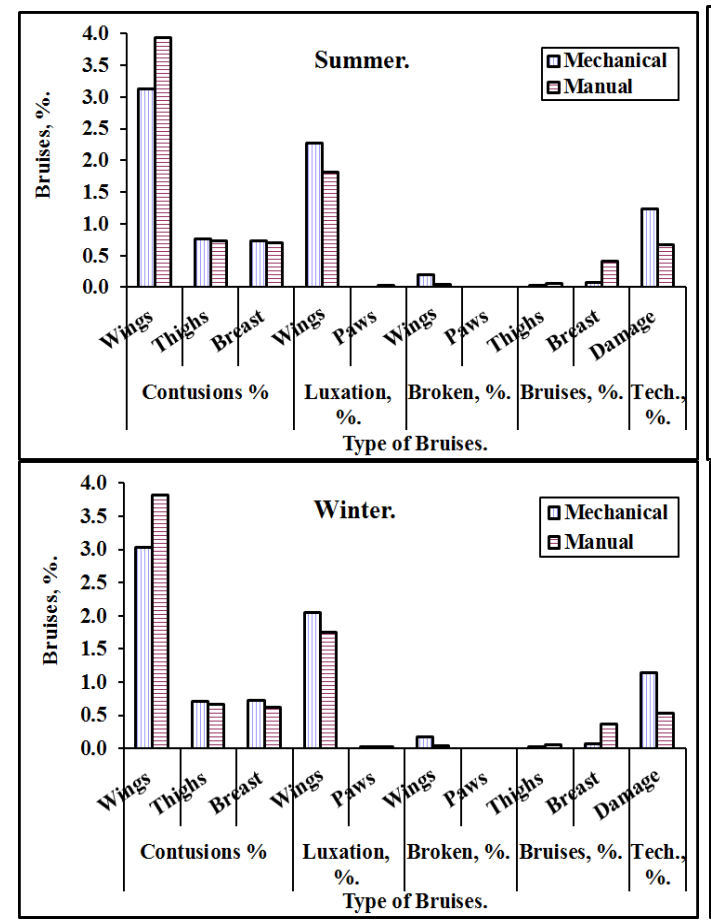

$\mathrm{MBM}=2000 \mathrm{~g}$.

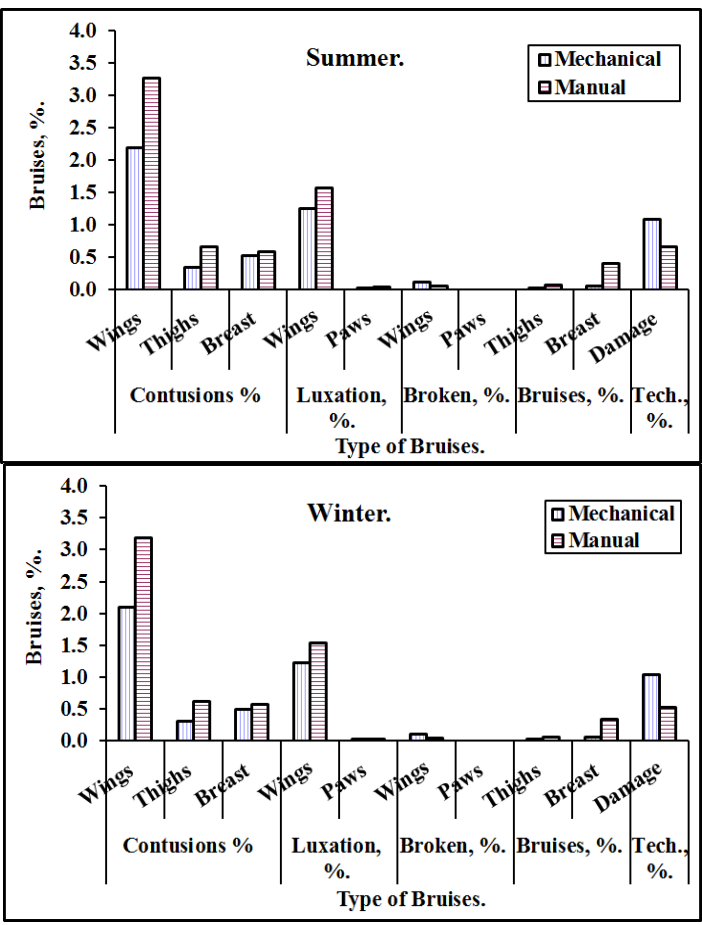

$\mathrm{MBM}=1600 \mathrm{~g}$.

Fig. 10: Effect of catching method, MBM and season on bruises \% at transport distance of $100-150 \mathrm{~km}$.

\section{(6): Effect of catching method on carcasses quality.}

Table2: shows effect of catching method on carcasses quality grade. On average, $95.13 \%$ of the broilers caught mechanically were included into the first quality grade, with standard error 0.088. For manual catching 94.6\% of the broilers were included into the first quality grade. The standard error was 0.034. Meanwhile, $0.839 \%$ of broilers caught mechanically were included into the second quality grade. Averaged 1.19 $\%$ of broilers caught manually with standard error of 0.0115 ) were included into second quality grade. For the third grade, $4.03 \%$ of broilers 
were caught mechanically with standard error 0.027 while the corresponding value with manual method was $4.19 \%$ with standard error 0.029. the present results were in agreement with those reported by Barbut et al. (1990) Many factors affect final product quality of the meat. Bruising and injury during harvesting and transportation are very important and should be avoided as much as possible as they cause unnecessary and costly trimmings and downgrading. Also, Kannan et al. (1996) mentioned that, an increase in the corticosterone concentration before slaughter is not desirable because it is associated with a higher hue value, indicating that the meat becomes lighter and less red in color. Thus, high stress levels in broilers may cause the production of paler thigh meat.

Table2: Effect of catching method on carcasses quality grade.

\begin{tabular}{|c|c|c|}
\hline Quality Grade & Mechanical catching & Manual catching \\
\cline { 2 - 3 } & Average \pm SE & Average \pm SE \\
\hline Class I & $95.13 \pm 0.088$ & $94.60 \pm 0.034$ \\
\hline Class II & $0.839 \pm 0.086$ & $1.19 \pm 0.0115$ \\
\hline Class III & $4.03 \pm 0.027$ & $4.19 \pm 0.029$ \\
\hline
\end{tabular}

\section{CONCLUSION}

Form the obtained results of the current research, we can conclude that:

1- For optimizing the performance rate of "CIEMME Super Apollo L", catching machine, the following conditions must be met:

- Operate the machine at forward speed of $0.1 \mathrm{~m} / \mathrm{sec}$. and collection belt speed of $0.65 \mathrm{~m} / \mathrm{sec}$. to improve the overall evaluation parameters.

- Operate the machine by a well-trained catching crew.

- Picking up the dead birds just before operating the machine reduces the rate of DOA.

2- Manual catching broilers at the last day of its life can result in unacceptably high levels of bruises, fractures and other traumatic injury, and even death to a significant number of broilers, as well as high stress levels.

3- Mechanical catching with "CIEMME Super Apollo L" catching machine frightened birds less than the manual method. It reduced the percentage of dead on arrival; the total bruises and reduces the percentage of the most bruises types. The only difference observed 
between mechanical and manual catching system was the frequent injuries at legs and wings.

4- The machine increased the performance rate with about $95 \%$ compared with manual catching and decreased the production cost from $44.7 \mathrm{~L} . \mathrm{E} /$ ton by manual to $9.48 \mathrm{~L} . \mathrm{E} /$ ton by the machine.

5- Mechanical catching with "CIEMME Super Apollo L" appears to be a good alternative for manual catching from the worker; bird's welfare and economic point of view, where the circumstances for the catchers are improved.

6- As there is a lack of knowledge about mechanical catching, this study will help to identify the optimum work conditions; merits and dismerits for the proposed catching machine to the society of commercial broiler producers in our country.

\section{REFERENCES}

Awady, M. N., 1978. Tractor and farm machinery, Text book, Fac. of Ag., Ain-Shams Univ.: 164-167.

Berry, P. S., P.J. Kettlewell and P. Moran, 1990. The AFRC Mark I. experimental broiler harvester. J.

Cockrem, J. F. 2007. Stress, corticosterone response and avian personalities. J. Ornithol. 148:169-178.

Delezie, E., 2006. Manual and mechanical catching and transport of broilers: Implications for welfare, physiology and product quality and ethical considerations. Ph.D Diss. Nr 721. K.U. Leuven, Leuven.

Delezie, E., D. Lips, R. Lips, and E. Decuypere, 2006. Is the mechanisation of catching broilers a welfare improvement? Anim. Welf. 15(2):141-147.

Delezie, E., D. Lips, R. Lips, and E. Decuypere, 2005. Mechanical catching of broiler chickens is a viable alternative for manual catching from an animal welfare point of view. 15(2):141-147. Animal sc. Papers and reports. 23 (1): 257-264.

Duncan, I. J. H. 1989. The assessment of welfare during the handling and transport of broilers. Proc. 3rd Eur. Symp. Poult. Welfare, Tours, France. WPSA, Beekbergen, Netherlands. Pp: 93-107 
Gocke A., 2000. Untersuchungüber den Einsatzeiner Hähnchenfang maschine in Mastbetrieben in Norddeutschland Doctoral Th. Vet. Med., Germany TierärztlicheHochschule Hannover

Gregory N.G., 1998. Animal Welfare and Meat Science.CABI Publ., Ch. 10: 183-194.

Gregory N.G., Austin S.D., 1992. Causes of trauma in broilers arriving dead at poultry processing plants. Veterinary Rec., 131: 501-503.

Jones, R.B. 1992. The nature of handling immediately prior to test affects tonic immobility fear reactions in laying hens and broilers. Appl. Anim. Behav. Sci. 34:247-254.

Kannan, G. and J. A. Mench, 1996. Influence of different handling methods and crating periods on plasma corticosterone levels inbroilers. Br. Poult. Sci. 37:21-31.

Knowles T.G., Broom D.M., 1990. The handling and transport of broilers and spent hens. Applied Animal Behaviour Sc., 28: 75-91.

Lacy, M. P. a Czarick, M., 1998. Mechanical harvesting of broilers. Poultry Sc., 77, 12: 1794-1797. ISSN 1525-3171.

Löhren, U., 2012. Overview on current practices of poultry slaughtering and poultry meat inspection. External scientific report, The European food Safety Authority, EN-298. 5-8. Available online: www.efsa.europa.eu/publications

M.A.E.A.S., 2015. Animal wealth statistics. Ministry of Ag. Ec. Affairs Sector, Ag. Stat., Vol. (2): 337-338.

Nijdam, E., Zailan, A.R.M., Van Eck, J.H.H., Decuypere, E. and Stegeman, J.A., 2006. Pathological features in dead on arrival broilers with special reference to heart disorders', Poultry Sc., 85,: 1303-1308.

Nijdam, E., Delezie E., Lambooij, E., Nabuurs M.J.A., Decuypere E., and Stegeman J.A., 2005. Processing, products, and food safety comparison of bruises and mortality, stress parameters, and meat quality in manually and mechanically caught broilers. Poultry Sc., 84: 467-474.

Nijdam, E., Arens, P., Lambooij, E., Decuypere, E. and Stegeman, J. A., 2004. Factors influencing bruises and mortality of broilers during 
catching, transport, and lairage. Poultry Sc., 83, 9: 1610-1615. ISSN 1525-3171.

Ramasamy, S., E.R. Benson and G.L. Van Wicklen. 2004. Efficiency of a commercial mechanical chicken catching system. J. Appl. Poult. Res. 13(1):19.

Remmer, M., 2011. Chicken Cat, Automated catching machines. Personal communications (orally or per email): cited by Löhren, U., 2012. Overview on current practices of poultry slaughtering and poultry meat inspection. European Food Safety Authority.

SCAHAW, 2000. Scientific Committee on Animal Health and Animal Welfare. The Welfare of Chickens Kept for Meat Production (Broilers). European Commission, Health and Consumer Protection Directorate General.

Schilling, M.W., Radhakrishnan, V., Thaxton, Y.V., Christensen, K., Thaxton J.P. and Jackson, V., 2008. The effects of broiler catching method on breast meat quality. Meat Sci. Jour., 79, 1: 163-171.

Steinhauser, L. a kol.: Produkce masa. Nakladatelství Last, Brno, 2000, 464s., ISBN 80-900260-7- 9.

Whiting, T. L., Mairead, E. D. a Rasali, D. P., 2007. Warm weather transport of broiler chickens in Manitoba II. Truck management factors associated with death loss in transit to slaughter. Canadian Vet. J., 48, 2: 148-154. ISSN: 0830-9000.

Zulkifli, I. M., T. Che Norma, C. H. Chong and T. C. Loh. 2000.Heterophil/lymphocyte and tonic immobility reactions to preslaughter handling in broiler chickens treated with ascorbic acid. Poult. Sci. 79:402-406.

\section{الملخص العربي (م المي}
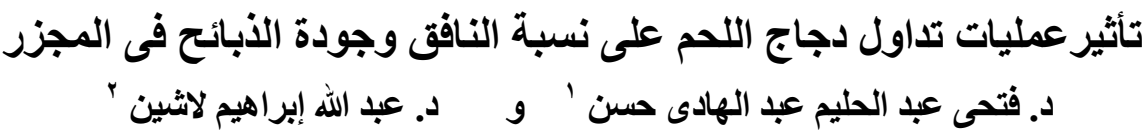

اجريت هذه الدراسة بمزارع ومجزر شركة الوطنية للدو اجن بوادى النطرون خلال الفترة من

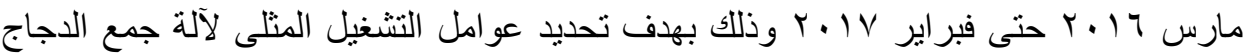

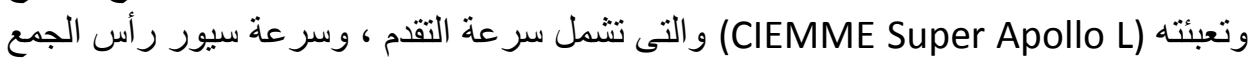
و الفئة الوزنية للاجاج، و علاقتها بالإنتاجية ونسبة الفو اقد أثناء التشغيل، ولنه

1 - باحث ، قسم نظم الهندة الحيوية،معهز بحوث الهندسة الزراعية، مركز البحوث الزراعية، مصر.

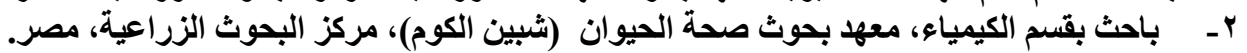


وكذلك مقارنة تأثير استخدام الآلة المقترحة عند المستويات المثلى لعو امل التشغيل مع الطريقة

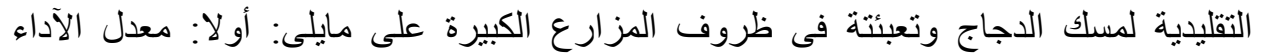

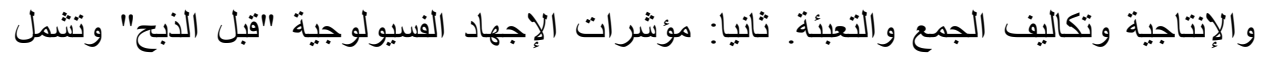
تركيز هرمون الكورتيكوستيرون والأدرينوكورتيكوتروفلك وتركيز الجلوكوز واللكتينيت في الإنى

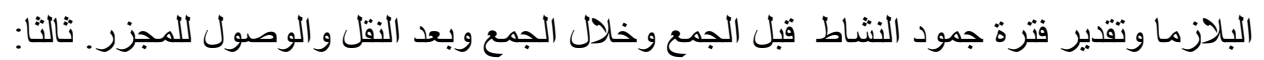

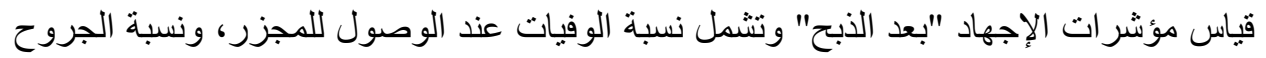

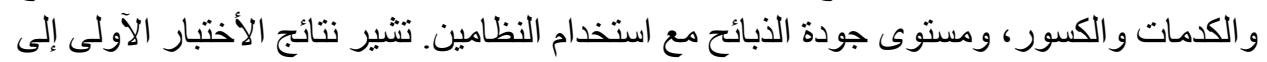

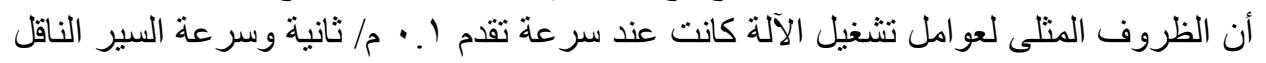

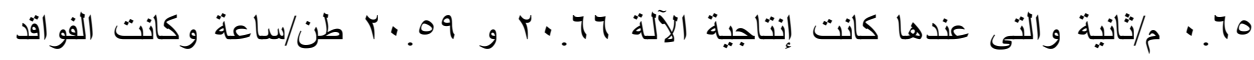

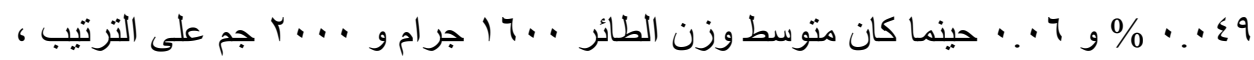

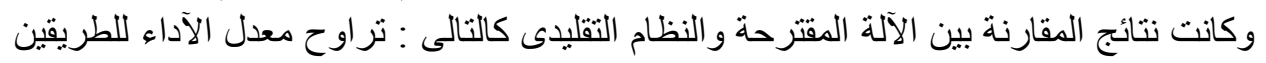

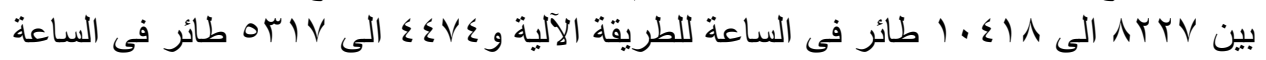

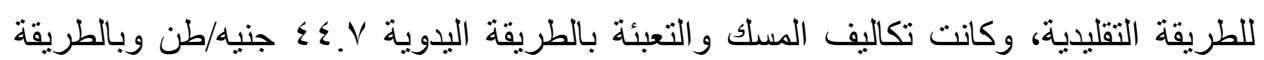

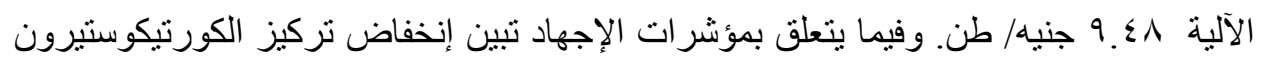

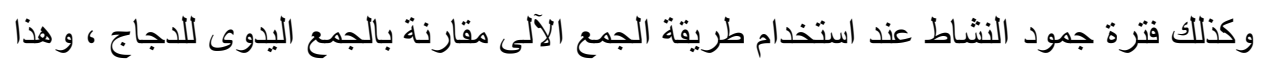

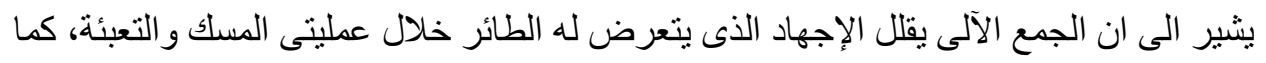

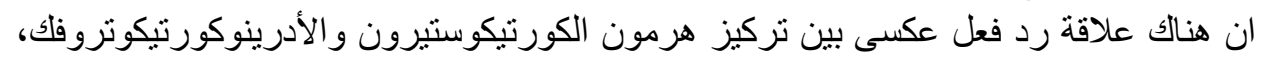

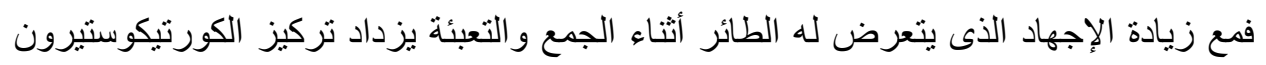

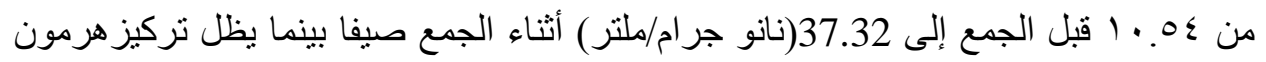

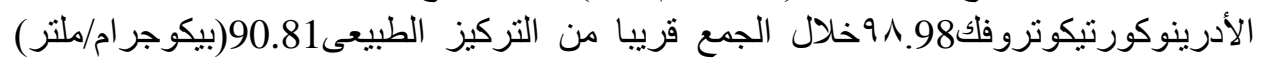

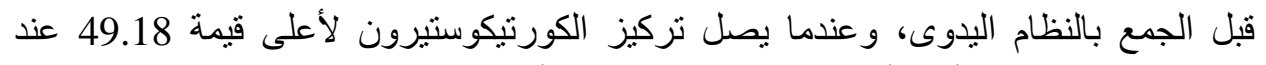

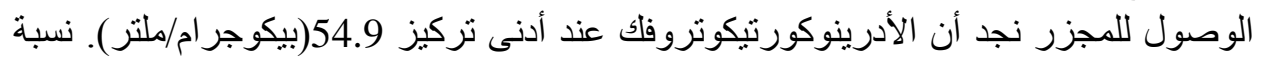

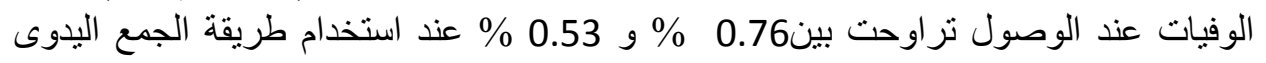

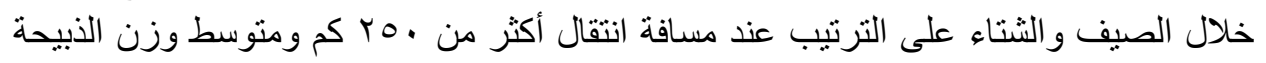

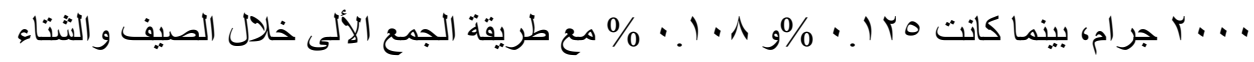

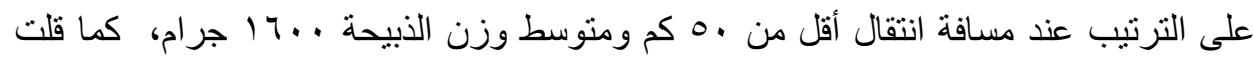

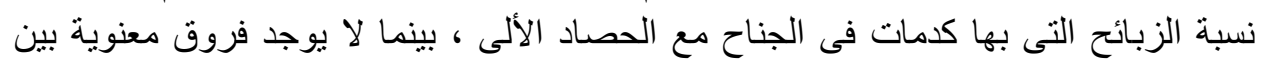

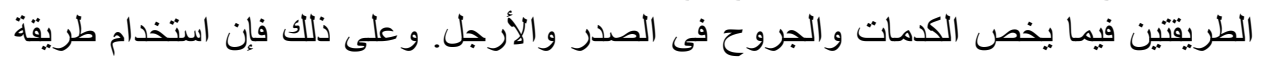

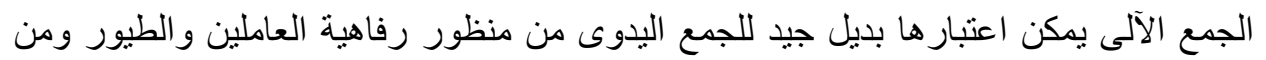

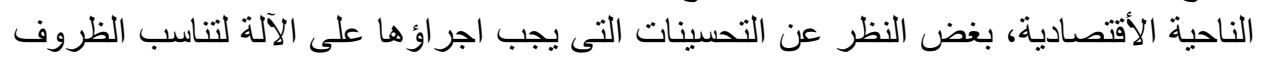

